\title{
Potential role of phytochemicals in metabolic syndrome prevention and therapy
}

This article was published in the following Dove Press journal:

Diabetes, Metabolic Syndrome and Obesity: Targets and Therapy

\author{
Francesco Francini-Pesenti ${ }^{1}$ \\ Paolo Spinella' \\ Lorenzo A Calò ${ }^{2}$ \\ 'Department of Medicine (DIMED), \\ Nutrition Unit, University of Padova- \\ Azienda Ospedaliera, Padova, Italy; \\ ${ }^{2}$ Department of Medicine (DIMED), \\ Nephrology, Dialysis and Transplantation \\ Unit, University of Padova-Azienda \\ Ospedaliera, Padova, Italy
}

\begin{abstract}
Metabolic syndrome (MetS) is a set of cardiovascular risk factors which severely increases the risk of type II diabetes, renal disease and cardiovascular disease. Over the last decades, the role of dietary bioactive substances in features of MetS has been extensively investigated. Due to their multiple properties, these plant-derived natural compounds have demonstrated to provide positive effects in obesity, diabetes, renal and in cardiovascular disease. Catechins of green tea and caffeine reduce body mass index and waist circumference. Catechins, anthocyanins and proanthocyanidins of cocoa reduce blood pressure and blood glucose. Curcumin and silymarin exert hepatoprotective effects. Monacolins of red yeast rice are effective cholesterol-lowering agents. However, inconsistent or conflicting results have been found in clinical trials when other promising compounds in vitro or in animal studies, such as policosanol, curcumin or silymarin, were used. Low oral bioavailability of substances, ineffective dosages, inadequate treatment duration and insufficient statistical approach may explain the lack of effectiveness observed in some human studies. Further clinical studies are needed to better understand the role of bioactive compounds in the prevention and management of MetS.
\end{abstract}

Keywords: metabolic syndrome, bioactive substances, nutrition, cardiovascular risk

\section{Introduction}

Metabolic syndrome (MetS) is defined as a cluster of metabolic disorders related to increased risk of cardiovascular disease, type 2 diabetes mellitus, renal disease and cognitive deficits. ${ }^{1}$ The condition includes hypertension, high blood glucose, excess of abdominal fat, hypertriglyceridemia, low high-density lipoprotein cholesterol (HDL-C). In 1998, WHO firstly proposed a definition for MetS. ${ }^{2}$ Over the last 20 years, other organizations have developed different definitions for this condition. In 2001, the National Cholesterol Education Program Adult Treatment Panel III included in the MetS criteria the fasting blood plasma glucose level. ${ }^{3}$ Subsequently, the International Diabetes Federation proposed a new definition of the MetS, listing ethnic group-specific thresholds for waist circumference to define central adiposity. ${ }^{4}$ The American Heart Association/National Heart, Lung, and Blood Institute (AHA/NHLBI) established that MetS is diagnosed when three or more of the following criteria are present: waist circumference $>102 \mathrm{~cm}$ in men, and $>88 \mathrm{~cm}$ in women, blood pressure $\geq 130 / \geq 85 \mathrm{mmHg}$, triglyceride (TG) plasma level $\geq 150 \mathrm{mg} / \mathrm{dL}(1.7 \mathrm{mmol} / \mathrm{L})$, HDL cholesterol $<40 \mathrm{mg} / \mathrm{dL}(1.03 \mathrm{mmol} / \mathrm{L})$ in men, and $<50 \mathrm{mg} / \mathrm{dL}(1.29 \mathrm{mmol} / \mathrm{L})$ in women, and fasting plasma glucose $\geq 100$ $\mathrm{mg} / \mathrm{dL}(5.6 \mathrm{mmol} / \mathrm{L})$ or history of diabetes mellitus or taking antidiabetic medications (Table 1). ${ }^{5}$
Correspondence: Lorenzo A Calò Department of Medicine, Nephrology, Dialysis and Transplantation Unit, University of Padova-Azienda

Ospedaliera, Via Giustiniani 2, Padova 35 I28, Italy

Tel +3904982I 307I

Fax +390498217921

Email renzcalo@unipd.it 
Table I Definitions of metabolic syndrome

\begin{tabular}{|c|c|}
\hline WHO 1999 & $\begin{array}{l}\text { IGT or DM, and/or IR, together with two or more of the following criteria: } \\
\text { - HDL-cholesterol }<0.9 \mathrm{mmol} / \mathrm{L}(35 \mathrm{mg} / \mathrm{dL}) \text { in men, }<1.0 \mathrm{mmol} / \mathrm{L}(40 \mathrm{mg} / \mathrm{dL}) \text { in women } \\
\text { - Triglycerides }>1.7 \mathrm{mmol} / \mathrm{L}(150 \mathrm{mg} / \mathrm{dL}) \\
\text { - Waist/hip ratio }>0.9 \text { (men) or }>0.85 \text { (women) or } \mathrm{BMI}>30 \mathrm{~kg} / \mathrm{m} \\
\text { - Blood pressure }>140 / 90 \mathrm{mmHg}\end{array}$ \\
\hline NCEP ATP III 200 I & $\begin{array}{l}\text { Three or more of the following criteria: } \\
\text { - Blood glucose greater than } 5.6 \mathrm{mmol} / \mathrm{L}(100 \mathrm{mg} / \mathrm{dL}) \text { or drug treatment for elevated blood glucose } \\
\text { - HDL-cholesterol }<1.0 \mathrm{mmol} / \mathrm{L}(40 \mathrm{mg} / \mathrm{dL}) \text { in men, }<1.3 \mathrm{mmol} / \mathrm{L}(50 \mathrm{mg} / \mathrm{dL}) \text { in women or drug treatment for low HDL-C } \\
\text { - Blood triglycerides }>1.7 \mathrm{mmol} / \mathrm{L}(150 \mathrm{mg} / \mathrm{dL}) \text { or drug treatment for elevated triglycerides } \\
\text { - Waist }>102 \mathrm{~cm} \text { (men) or }>88 \mathrm{~cm} \text { (women) } \\
\text { - Blood pressure }>130 / 85 \mathrm{mmHg} \text { or drug treatment for hypertension }\end{array}$ \\
\hline AHA/NHLBI 2004 & $\begin{array}{l}\text { Three or more of the following criteria: } \\
\text { - Waist circumference }>102 \mathrm{~cm} \text { in men and }>88 \mathrm{~cm} \text { in women } \\
\text { - Blood pressure } \geq 130 / \geq 85 \mathrm{mmHg} \text { or specific medication } \\
\text { - Triglyceride plasma level } \geq 150 \mathrm{mg} / \mathrm{dL}(\mathrm{I} .7 \mathrm{mmol} / \mathrm{L}) \\
\text { - HDL-cholesterol }<40 \mathrm{mg} / \mathrm{dL}(1.03 \mathrm{mmol} / \mathrm{L}) \text { in men and }<50 \mathrm{mg} / \mathrm{dL}(1.29 \mathrm{mmol} / \mathrm{L}) \text { in women } \\
\text { - Fasting plasma glucose } \geq 100 \mathrm{mg} / \mathrm{dL}(5.6 \mathrm{mmol} / \mathrm{L}) \text { or history of diabetes mellitus or taking antidiabetic medications }\end{array}$ \\
\hline IDF 2005 & IDF definition are very similar to NCEP ATP III except in the waist parameter of $102 \mathrm{vs} 94 \mathrm{~cm}$ in men and $88 \mathrm{vs} 80 \mathrm{~cm}$ in women. \\
\hline
\end{tabular}

Abbreviations: AHA/NHLBI, American Heart Association/National Heart, Lung, and Blood Institute; DM, diabetes mellitus; HDL-C, high-density lipoprotein cholesterol; IDF, International Diabetes Federation; IGT impaired glucose tolerance; IR, insulin resistance; NCEP ATP III, Cholesterol Education Program Adult Treatment Panel III.

During the past several decades, the prevalence of metabolic syndrome has markedly increased worldwide. The global prevalence of this disorder is reported between $14 \%$ and $32 \%$, which increases with aging in both sexes. ${ }^{6,7}$

Insulin resistance (IR) plays a key role in the pathophysiology of the MetS and it is considered to be a causative factor also for non-alcoholic fatty liver disease (NAFLD), conditions often associated with MetS. ${ }^{8}$ IR leads to higher levels of serum insulin and glucose and favors the development of diabetes mellitus; moreover, hyperinsulinemia results in excessive renal sodium retention and elevations in blood pressure. ${ }^{9}$

It is not still clear what causes MetS, but it is known that a chronic, subclinical inflammation is associated with MetS. Liver, intestine and adipose tissue are the three major sites that have been involved in initiating of chronic inflammation in MetS. ${ }^{10}$ Adipose tissue excess induces a proinflammatory state due to hypertrophy of adipocytes. ${ }^{11}$ Hypertrophic adipocytes secrete proinflammatory cytokines, such as tumor necrosis factor alpha (TNF $\alpha$ ), IL-6, IL-8 and MCP-1. Proinflammatory cytokines cause serine phosphorylation of insulin receptor substrate-1 via nuclear factor $\mathrm{kB}(\mathrm{NF \kappa B})$ and Jun $\mathrm{N}$-terminal kinase signaling inducing IR. ${ }^{12}$ Adipocyte hypertrophy causes hypoxia and thus can induce cell necrosis with the production of $\mathrm{TNF} \alpha$, IL-6, plasminogen activator inhibitor-1 (PAI-1), and macrophage infiltration. ${ }^{13}$ In turn, TNF $\alpha$ enhances IR in adipose cells.

NAFLD is often found in patients with metabolic syndrome. ${ }^{14}$ Most patients with NAFLD remain asymptomatic but about the $20 \%$ progress to non-alcoholic steatohepatitis (NASH), a chronic hepatic inflammation. ${ }^{15}$ Both MetS and NAFLD are associated with alterations in the gut flora and its related biological pathways. Changes in intestinal inflammation, gut permeability, energy provision, anaerobic fermentation and IR have been described. ${ }^{12}$ Substances derived from the gut microbiota such as lipopolysaccharides, peptidoglycan and bacterial DNA can reach the liver through the portal vein and activate the Kupffer cells, activating an inflammatory cascade that favors NASH and IR. ${ }^{16}$

The gut microbiota can affect IR via several mechanisms. For example, the stimulation of toll-like receptors by bacterial lipopolysaccharides induces the activation of serine kinases, leading to IR through serine phosphorylation of insulin receptor substrate- $1 .{ }^{17}$

First-line treatment of MetS consists of lifestyle changes, including diet and physical activity. The Mediterranean diet and other dietary regimens rich in vegetable-derived products were shown to prevent MetS. ${ }^{18,19}$ The favorable effects of these diets are thought to be related to their content of bioactive substances, 
monounsaturated and polyunsaturated fatty acids. ${ }^{20}$ Although low-density lipoprotein cholesterol (LDL-C) does not explicitly belong to MetS, subjects with MetS have a high concentration of small dense LDL particles and a low LDL-C/HDL-C ratio, ${ }^{21}$ both powerful atherogenic risk factors. When lifestyle changes alone are unsuccessful, phytochemicals can contribute to improve lipid profile.

Bioactive compounds are plant secondary metabolites found in foods able to modulate metabolic processes. Research on phytochemicals suggests their possibility as therapeutic and preventive agents against diseases including inflammation, oxidative stress, dyslipidemia and IR. This review addresses current knowledge about the phytochemicals in the treatment of MetS components and in other alterations that often are associated with MetS, such as NAFLD and high cholesterol levels.

\section{Bioactive compounds: classes and dietary sources \\ Polyphenols}

Most bioactive natural substances are polyphenols. They are a large group of secondary metabolites of plants that are generally involved in defense mechanisms against ultraviolet radiation or pathogens. More than 8000 polyphenolic compounds have been identified in various plant species.

Polyphenols may be classified according to the number of phenol rings of their molecular structure and on the basis of functional groups linked to these rings in two main classes: flavonoids and non-flavonoids (phenolic acids, stilbenes and lignans).

Flavonoids have a common basic structure consisting of two aromatic rings ( $\mathrm{A}$ and $\mathrm{B}$ ) bound together by three carbon atoms that form an oxygenated heterocycle (ring $\mathrm{C}$ ). These substances are widely present in the plants and they are responsible for the attractive colors of the flowers, fruits and leaves. Until now more than 4000 varieties of flavonoids have been identified. Flavonoids may be divided into 6 subclasses based on the type of heterocycle involved: flavonols, flavones, isoflavones, flavanones, anthocyanidins and flavanols (catechins and proanthocyanidins). ${ }^{22}$

Phenolic acids are divided into two subclasses: derivatives of benzoic acid and derivatives of cinnamic acid. The hydroxybenzoic acid content of edible plants is low in most cases, except for certain red fruits, black radish and onions. Tea is a rich source of gallic acid. Hydroxybenzoic acids are constituent of hydrolyzable tannins (gallotannins in mangoes and ellagitannins in red fruit including strawberries, raspberries and blackberries). ${ }^{23}$

The most common hydroxycinnamic acids are p-coumaric, caffeic, ferulic and sinapic acids. ${ }^{24}$ They are found in the free form almost exclusively in processed food. They are glycosylated derivatives or esters of quinic acid, shikimic acid and tartaric acid. Caffeic acid occurs in foods mainly as an ester with quinic acid called chlorogenic acid, a compound that is found in several types of fruit and in high amounts in coffee. Ferulic acid is the most abundant phenolic acid found in cereal grains, which are its main dietary source.

Stilbenes consist of two benzene rings connected by a two-carbon methylene bridge. The provision of stilbenes with the human diet is quite low. Most stilbenes in plants act as antifungal phytoalexins, compounds that are synthesized in response to infection or injury. Resveratrol $\left(3,4^{\prime}, 5\right.$ trihydroxystilbene), the stilbene most studied, is largely found in berries, grapes and in red wine as cis and trans isomeric forms, mostly glycosylated. ${ }^{25}$

Lignans are formed of 2 phenylpropane units. Several lignans, such as secoisolariciresinol, are considered to be phytoestrogens. Oleaginous seeds (linseed) are the richest source of lignans while legumes, cereals, vegetables (garlic, asparagus, carrots) and fruit (pears, prunes) as minor sources. $^{26}$

\section{Other bioactive compounds}

Some terpenoids and sterols derived from terpenoid precursors have been used for the treatment of the MetS features. $^{27}$ Terpenoids consist of five-carbon isoprene units and so can also be called "isoprenoids". Molecules with multiples of 5 carbons and particularly with single carbon side chains belong to this group. The carotenoids are a large family of yellow to orange pigments built up from eight isoprene units (40 carbons). Beta-carotene is best-known as the pigment of the carrot and it is a precursor of vitamin A. Phytosterols, including phytostanols and their esters, are more complex terpenoids occurring in plant cell membranes and present in the highest amounts in vegetable oils, nuts and seeds. Sitosterol, campesterol and stigmasterol are the most frequent plant sterols in food and represent about in media $65 \%, 30 \%$ and $3 \%$ of dietary intake. $^{28}$

Monacolin $\mathrm{K}$ and other monacolins are natural statins produced by Monascus purpureus yeast and found in the red yeast rice (RYR) used in China and other Asian 
countries for centuries as a traditional medicine. They are a class of molecules with a polyketide structure, able to inhibit hydroxymethyl glutaryl-coenzyme A reductase, the key enzyme in cholesterol biosynthesis. ${ }^{29}$

Policosanol (PC) is a mixture of very long chain aliphatic alcohols (24-34 carbons) originally isolated from sugarcane (Saccharum officinarum L.). The major components of the policosanol mixture are octacosanol $(60-70 \%, \mathrm{w} / \mathrm{w})$, triacontanol (10-20\%, w/w) and hexacosanol (4-10\%, w/w). PC can also be extracted from a variety of other natural sources such as bee wax, rice bran and wheat germ. ${ }^{30}$

\section{Treatment of metabolic syndrome by bioactive compounds Polyphenols}

Several foods and beverages containing polyphenols have been found to be useful in the MetS features. Green tea, nuts, red wine, grape seeds, berries and dark chocolate, which contain both flavanol monomeric forms (catechins) and their oligomers (proanthocyanidins), are the main sources of these substances. ${ }^{31}$ Green tea, that is sourced from the fresh leaves of the Camellia sinensis L. plant, contains high levels of flavanols (catechins) and the alkaloid caffeine, both virtually able to produce metabolic effects.

Nagao et $\mathrm{al}^{32}$ reported a significant reduction of body weight, BMI, waist circumference and body fat mass in men treated for 12 weeks with a green tea extract (catechins $690 \mathrm{mg}$ per day) compared with the control group (catechins $22 \mathrm{mg}$ per day). As caffeine has been found to influence the energy balance by increasing energy expenditure and decreasing energy intake, ${ }^{33}$ the authors adjusted caffeine intake in both groups and ascribed the effects to catechin intake.

Basu et $\mathrm{al}^{34}$ treated 35 MetS subjects randomly assigned to three groups: control, green tea beverage and green tea extract. After 8 weeks, body weight and BMI decreased significantly both in green tea beverage group $\left(-2.5 \pm 0.7 \mathrm{~kg}\right.$ and $-0.9 \pm 0.3 \mathrm{~kg} / \mathrm{m}^{2}$, respectively) and in green tea extract group $(-1.9 \pm 0.6 \mathrm{~kg}$ and -0.7 $\pm 0.2 \mathrm{~kg} / \mathrm{m},{ }^{2}$ respectively) compared to controls, without changes in body fat and waist circumference. Suliburska and coworkers ${ }^{35}$ observed that the 12 weeks of supplementation with $378 \mathrm{mg}$ of green tea containing $208 \mathrm{mg}$ of epigallocatechin gallate (EGCG) per day significantly decreased BMI and waist circumference in obese patients.

The effects of the tea on body weight depend mainly on the effect of caffeine and catechins on the adrenergic system. Caffeine (1,3,7 trimethylxantine) is a purine alkaloid inhibiting the phosphodiesterase enzyme that hydrolyzes cyclic adenosine monophosphate (cAMP) to AMP. ${ }^{36}$ cAMP signal is activated by beta-adrenergic stimulation, inducing some adrenergic effects including appetite reduction and increase of energy expenditure and lipolysis. ${ }^{37}$ Moreover, caffeine enhances the expressions of the uncoupled proteins that increase thermogenesis through enabling phosphodiesterase inhibition and protein kinase A activating by cAMP. ${ }^{36}$ The thermogenic effect of caffeine is prolonged $30-150$ mins after caffeine consumption, according to the dose. ${ }^{38}$ The catechins of green tea interfere also with catecholamine inactivation, inhibiting the catechol-O-methyl transferase enzyme (COMT) and inducing a adrenergic overstimulation. ${ }^{39}$ Similar to the caffeine-induced inhibition of phosphodiesterase, the COMT inactivation increases the energy expenditure, fat oxidation and lipolysis. ${ }^{36}$

On the other hand, the studies that evaluated the effects of different doses of the green tea catechins on the energy expenditure $^{40}$ and on body mass index (BMI) and waist circumference $^{41}$ showed no significant effect. In a study evaluating the effects in thermogenesis of different ECGC doses $(90,200,300$, or $400 \mathrm{mg})$ administered mixed to $200 \mathrm{mg}$ of caffeine. Compared to placebo without caffeine, the $24 \mathrm{hrs}$ of energy expenditure in EGCG and caffeine groups raised by $8 \%$ and this increase was similar to all doses of EGCG in the mixtures. ${ }^{42}$

Few studies evaluated the effects of green tea catechins free from caffeine on thermogenesis. Boschmann et al. ${ }^{43}$ treated 6 obese subjects with EGCG $300 \mathrm{mg}$ daily for 2 days without observing a significative change in the preprandial and postprandial energy expenditure.

The effect of green tea on energy expenditure seems to occur when the green tea catechin is administered combined with caffeine. In a study, 31 thin young males and 31 thin young females were given $94 \mathrm{mg}$ EGCG and $100 \mathrm{mg}$ caffeine-containing thermal drink, 3 times daily for 3 days. Following the consumption of thermal drink, a significant increase $(4.6 \%)$ in $24 \mathrm{hrs}$ of energy expenditure was found. ${ }^{44}$

One of the most important limitations of the studies examining the effect of green tea catechins and caffeine components on the thermogenesis is considered the variability among individuals about the habitual consume of caffeine and/or catechins. To verify this hypothesis, 76 overweight and moderately obese subjects on weight maintenance after body weight loss were treated with a 
green tea-caffeine mixture $(270 \mathrm{mg}$ EGCG $+150 \mathrm{mg}$ caffeine per day). ${ }^{45}$ Thermogenesis was lower and body weight regain was higher in the subjects that regularly consume high amounts of caffeine ( $>300 \mathrm{mg} /$ day).

The studies on the effects of green tea on the lipid profile have shown controversial effects. Green tea supplementation was shown to improve the lipid profile by reducing significantly LDL-cholesterol in some trials ${ }^{34,35,46,47}$ and/or TGs. ${ }^{35,4648}$ On the other hand, other studies did not find improvement in lipid profile using green tea. ${ }^{32,49,50}$ Green tea also reduces oxidative stress and cardiac remodeling in dialysis patients ${ }^{46}$ and counteracts inflammation in the nervous system. ${ }^{52}$

Anthocyanins are water-soluble bioactive compounds widely found in various vegetables and fruits, including grapes, plums, cherries, cranberries, strawberries, blueberries, blackberries, elderberries, currants, beetroot, red cabbage and red onions. These substances have antioxidant property due to their ability to transfer electrons or to donate the hydrogen atoms from various hydroxyl groups to free radicals. ${ }^{53}$ Animal studies showed that anthocyanins are mainly absorbed in the intact glycosidic form and they are found in the systemic circulation within $0.25-2$ hrs. Their plasma concentration declines rapidly within 2 hrs upon a single oral administration in rats. ${ }^{54}$

Blueberries (Vaccinium myrtillus L.) are fruits rich in anthocyanidins, chlorogenic acid, flavonoids and stilbenes, such as pterostilbene and resveratrol. Studies on blueberries showed several preventive and therapeutic properties, including the reduction of oxidative stress and inflammatory responses, ${ }^{55}$ protecting against cardiovascular disorders, hypertension ${ }^{56}$ and diabetes. ${ }^{57}$

Blueberry-enriched diet evidenced a protective effect on the MetS-related pro-inflammatory status in the obese Zucker rat increasing adiponectin expression and suppressing liver expression of NF-kB. ${ }^{58} \mathrm{An}$ in vivo study showed that blueberry reduced TGs, body weight gain, liver weight, abdominal fat mass, and improved adipose and skeletal muscle peroxisome proliferator activated receptor activities involved in glucose uptake and in glucose and fat oxidation in obese rats. ${ }^{59}$ A meta-analysis of 32 clinical studies evidenced that anthocyanidin-rich foods ameliorate glycemic control and exert favorable effects on low-density plasma cholesterol (LDL-C) level. ${ }^{60}$ In a randomized controlled study, 48 patients with MetS were supplemented with freeze-dried and fresh strawberries for 8 weeks daily decreased total cholesterol, LDL-C, small low-density lipoprotein particles and circulating levels of vascular cell adhesion molecule respect to controls. ${ }^{61}$ Castro-Acosta et $\mathrm{al}^{62}$ in a randomized, controlled, double-blinded cross-over trial showed that apple and blackcurrant polyphenols decreased postprandial glucose, insulin and C-peptide excursion and probably due to inhibition of intestinal glucose transport. An anthocyanin-rich beverage (açai berries beverage) was administered to 37 subjects with MetS for 12 weeks. ${ }^{63}$ The plasma levels of interferon gamma (IFN- $\gamma$ ) and urinary level of 8-isoprostane were decreased. However, all parameters related to the glucose and lipid metabolisms were found to be unchanged after intake of the beverage.

Pomegranate (Punica granatum Linn) is a fruit cultivated since ancient times throughout the Mediterranean region. Pomegranate is rich in polyphenols such as ellagitannins and anthocyanin and therefore it has been proposed in the prevention and treatment of MetS. In vivo studies evidenced that pomegranate reduces blood glucose, increases insulin sensitivity, inhibits $\alpha$-glucosidase and enhances the glucose transporter type 4 activity. ${ }^{64}$ Moreover, pomegranate exerts anti-inflammatory effects, acting through the modulation of peroxisome proliferator-activated receptor pathways ${ }^{64}$ and a recent trial evidenced that this fruit reduces blood pressure in subjects with MetS. ${ }^{65}$ Cocoa is a rich source of polyphenols such as catechins, anthocyanins and proanthocyanidins. Epidemiological data and short-term human intervention studies evidenced that the cocoa polyphenols exert cardiovascular benefits of in humans. ${ }^{66}$ Vasodilation is the main vascular effect observed as a consequence of nitric oxide (NO) release following acute cocoa ingestion. ${ }^{67}$ Dark chocolate was more effective than white chocolate in lowering the flow-mediated dilation and the blood pressure. ${ }^{68}$ Cocoa polyphenols exert antioxidant and anti-inflammatory effects acting on some important signaling pathways such as tolllike receptor $4 / \mathrm{NFKB}$ signal transduction and activation of transcription. ${ }^{69}$ Cocoa polyphenols induce release of NO through the activation of endothelial NO synthase which, in turn, accounts for vasodilation and cardioprotective effects. In healthy individuals, the consumption of $45 \mathrm{~g}$ of flavonoidrich dark chocolate increased coronary flow velocity reserve respect to flavonoid-free white chocolate. ${ }^{70}$ Cocoa can reduce blood pressure through several mechanisms. Increase in NO may explain the anti-hypertensive effects of cocoa. ${ }^{71}$ Moreover, flavanols and flavonol are able to inhibit angiotensin-converting enzyme activity in vitro. ${ }^{72}$

Many studies found that cocoa, provided as chocolate bar or beverage, exerts favorable effects on glucose control. Cocoa and its flavonols improved insulin sensitivity 
and reduced blood glucose, insulin, and $\mathrm{HbA1c}$ in normoglycemic and prediabetic subjects and in patients with type 2 diabetes mellitus within 2-4 weeks. ${ }^{72,73}$ Despite these data, studies on long-term effects of cocoa are lacking. Interestingly, when epicatechin were utilized alone, no significant glycemic improvement was observed, ${ }^{74-76}$ meaning that synergistic combination of the bioactive compounds of cocoa is necessary to achieve the clinical effects. ${ }^{77}$ Studies in vitro and in animal models showed that polyphenols can induce an improvement of MetS features through several mechanisms including inhibition of digestive enzymes and intestinal glucose transporters, ${ }^{78}$ stimulation of incretin response, improvement of insulin signaling and modulation of gut microbiota. ${ }^{79}$

Curcumin is a polyphenol with several biologic activities derived from rhizomes of turmeric (Curcuma longa L.). In turmeric, there are two other analogs along with curcumin, called curcuminoids: demethoxycurcumin and bisdemethoxycurcumin. ${ }^{80}$ Curcumin and curcuminoids have low oral bioavailability due to limited intestinal absorption and rapid metabolism. ${ }^{81}$

Clinical studies have shown that this polyphenol exerts anti-inflammatory, anticancer, hypoglycemic, antioxidant, antiviral and antimicrobial activities, indicating that curcu$\min$ is a therapeutic potential against a wide range of human diseases. ${ }^{82}$ Curcumin has been also shown to directly interact with numerous cell signaling molecules involved in inflammation, cancer and other diseases. ${ }^{83}$ Moreover, curcumin modulates the activity of several transcription factors, growth factors, inflammatory cytokines, protein kinase and other enzymes. ${ }^{84}$ Several clinical studies have investigated the use of curcumin in the components of MetS. Yang et $\mathrm{al}^{85}$ in a randomized doubleblind controlled trial evaluated the effect of $1950 \mathrm{mg}$ daily of curcumin extract ( $95 \%$ curcuminoids) on weight, glucose and lipid profile in patients with MetS. After 12 weeks of treatment, the levels of HDL-C were significantly increased, while the levels of LDL-C were decreased. In a previous randomized double-blind controlled study, the supplementation with curcumin did not show any significant improvement on total cholesterol, LDL-C, HDL-C and TGs in 75 acute coronary syndrome patients. $^{86}$

In a systematic review and meta-analysis, Melo et $\mathrm{al}^{87}$ evidenced that the supplementation of curcuminoids and/ or curcumin decreased the concentrations of $\mathrm{HbAlc}$ without affecting homeostatic model assessment of insulin resistance (HOMA-IR). The administration of isolated curcumin or combined curcuminoids was both effective in lowering the fasting blood glucose concentrations of individuals with dysglycemia (pre-diabetes, diabetes or metabolic syndrome), but not in non-diabetic or euglycemic individuals. Unlike curcumin and curcuminoids, in this meta-analysis, the use of turmeric extracts was not effective.

In order to improve curcumin bioavailability, the substance was administered combined with piperine or as phytosomes. Piperine could improve curcumin bioavailability reducing liver conjugation and consequently its elimination by urine. ${ }^{88}$ Phytosomes are complexes of bioactive natural compounds and phospholipids. The amphipathic nature of phospholipids improves the bioavailability and protects the bioactive substances from degradation in the digestive tract. ${ }^{89}$ Panahi et al $^{90}$ treated with curcumin $(1000 \mathrm{mg} /$ day) plus piperine $(10 \mathrm{mg}$ /day $)$ 50 diabetic patients for a period of 3 months, evidencing a significant reduction in serum levels of glucose, $\mathrm{HbAlc}$, C-peptide and transaminases compared with the placebo group. Recently, Cicero et $\mathrm{al}^{91}$ treated with $200 \mathrm{mg}$ of phytosomial curcumin and $8 \mathrm{mg}$ of piperine per day 80 overweight subjects. HOMA-IR, waist circumference, blood pressure, TG, HDL-C, aspartate aminotransferase (AST), alanine aminotransferase (ALT), gamma-glutamyl transferase and serum cortisol significantly improved compared to the baseline.

Olive oil is considered as a functional food that, in addition to high level of oleic acid, contains minor components biologically active, such as vitamins and polyphenols. The phenol content in olive oil varies between oils. In refined oils, phenolic substances may be present at concentrations of approximately $62 \pm 12 \mathrm{mg} / \mathrm{kg}$, whereas in high-quality extra-virgin olive oils, the concentration may be much higher. ${ }^{92}$ Olive oil contains over 230 chemical compounds, including tocopherols, fatty alcohols, triterpenic alcohols, squalene, plant sterols and polyphenols such as oleuropein and its metabolites hydroxytyrosol and tyrosol. ${ }^{93}$ Polyphenols, in particular hydroxytyrosol and tyrosol, have been evidenced anti-inflammatory effects and may also influence cell proliferation and apoptosis in cancer cell. ${ }^{94}$

In the Primary Prevention of Cardiovascular Disease with a Mediterranean Diet (PREDIMED) study, extra-virgin olive oil improved blood pressure, glycaemic control, endothelial function, and oxidative stress, decreased triglycerides, total and LDL-C, increased HDL-C and reduced inflammatory markers such as C-reactive protein and 
IL- $6 .{ }^{95}$ In the large multi-center clinical trial EUROLIVE study (Effect of Olive Oil Consumption in European Populations), the consumption of olive oil with different phenolic concentrations increased HDL-C, decreased total cholesterol and oxidative stress markers and decreased TG plasma levels in a dose-dependent manner. ${ }^{96}$ A recent

meta-analysis of 30 intervention studies demonstrated that the impact of olive oil on glucose, TGs, and LDL-C is mediated through an adherence to the Mediterranean diet, with the only effect of olive oil polyphenols being the increase of HDL-cholesterol and the improvement of the antioxidant and inflammatory status of the subject. ${ }^{97}$

Some flavonoids and phenolic acids contained in elderflower extract, such as kaempferol, quercetin and their glucosides, can enhance the glucose and oleic uptake in human skeletal muscle cells and in hepatocytes in vitro. ${ }^{98}$ If these pieces of evidence will be confirmed by clinical trials, elderflower extract could be usefully employed as ingredient of supplements or functional food against diabetes or glucose abnormalities in MetS.

\section{Other bioactive compounds}

\section{Milk thistle}

Milk thistle (Silybum marianum L.) is a plant that has been used for centuries as a herbal treatment in liver and biliary tract diseases. ${ }^{99}$ Fruits and seeds of milk thistle contain the main active components of $S$. marianum that are a mixture of flavonolignans, called silymarin, containing silibinin A and $\mathrm{B}$, isosilybin $\mathrm{A}$ and $\mathrm{B}$, silychristin and silydianin. Silymarin has antioxidant and anti-inflammatory effects, ${ }^{100}$ promotes hepatocyte regeneration and inhibits fibrogenesis and then it is considered to have hepatoprotective effects. ${ }^{101}$ Animal studies showed that $S$. marianum can be effective in the treatment of MetS characteristics, including high glucose and lipid plasma levels, high blood pressure and liver steatosis. $^{102}$

A meta-analysis of 6 randomized and controlled clinical trials evaluated the effects of silymarin in patients with hepatic diseases. ${ }^{103}$ A statistically significant reduction of $0.26 \mathrm{IU} / \mathrm{mL}(p=0.007)$ of ALT and $0.53 \mathrm{IU} / \mathrm{mL}(p=0.000)$ of AST plasma level after using the silymarin was observed, though with no clinical relevance. In another meta-analysis of 8 randomized controlled trials involving 587 patients with NAFLD treated with silymarin was reported a reduction of the $\operatorname{AST}(6.5 \mathrm{U} / \mathrm{mL}, p=0.02)$ and ALT $(-9.6 \mathrm{U} / \mathrm{mL}, p=0.02)$ levels more significantly than the control group. ${ }^{104}$ Clinical trials evaluating the effects of milk thistle extracts showed no significant effects on blood pressure. ${ }^{105,106}$ Clinical studies on the silymarin use in diabetic patients reported controversial data, so that further studies are needed for more investigation. ${ }^{102}$

\section{Policosanol}

Dietary supplements containing PC extracted by sources other than sugarcane have been marketed in recent years as cholesterol-lowering agents. Their composition in longchain aliphatic primary alcohols differs little among the different sources and octacosanol is the main aliphatic primary alcohol in all policosanol mixtures and it is thought to be the most active component.

The mechanism behind the PC-induced cholesterol lowering has not yet been fully elucidated yet. Studies on humans and rats show that PC decreases in vitro LDL oxidation. ${ }^{107}$ Other studies examining the antioxidant activity of sugarcane PC failed to support previous positive findings, reporting no significant change of oxidation state in LDL from humans treated with sugarcane PC supplements. ${ }^{108,109}$ Early clinical studies have shown that oral administration of sugarcane PC within a range of 5-20 mg/day reduces plasma total cholesterol and LDL-C levels and increases HDL-C in healthy, hypercholesterolaemic and diabetic patients. ${ }^{110-112}$

Reports comparing sugarcane PCs with statins showed the same efficacy in LDL-C lowering, whereas sugarcane PCs have a greater efficacy than statins in increasing HDL-C. ${ }^{113-115}$ Sugarcane PC-induced cholesterol reduction seems to be dose-dependent in a dose range of 5-20 mg/day.

Others have not been able to reproduce the same evidence regarding PC supplementation. Indeed, the effects of PC on plasma cholesterol levels have been questioned by the results of several randomized controlled trials performed in Europe and the US that failed to find any significant effect of PC on plasma cholesterol levels in different clinical conditions. ${ }^{116-119}$ The lack of cholesterol-lowering efficacy has been confirmed for both sugarcane PC and for PC extracted from other sources. ${ }^{120,121}$ In 2011, EFSA rejected a claim on the beneficial effects of sugarcane PC for the lack of evidence of a cause-effect relationship between their supplementation and plasma cholesterol reduction. ${ }^{122}$ Recently, two studies showed that the short-term treatment with cuban policosanol can reduce blood pressure both in spontaneously hypertensive rat $^{123}$ and in healthy men, ${ }^{124}$ also improving lipid profile.

\section{Phytosterols}

Phytosterols are natural sterols that occur in the cells of all plants where they play an important role in stabilizing the biological membranes. A western-type diet contains about 
60-500 mg of plant phytosterols. ${ }^{125}$ Serum phytosterol levels in humans range from 7 to $41 \mu \mathrm{mol} / \mathrm{L}(2.9-17.0 \mathrm{mg} / \mathrm{L}){ }^{126}$ Only a negligible amount of phytosterols is absorbed in the healthy human gut. Phytosterols are absorbed under similar conditions needed for cholesterol absorption and compete for cholesterol in absorptive micelles resulting in reduced solubility of cholesterol. ${ }^{127}$ The transfer of plant sterols from the mixed micelles into the enterocytes occurs by the same intestinal membrane transporter, the Niemann-Pick C1-Like 1 protein, and then they compete with cholesterol for entry into cells. ${ }^{128}$

The low absorption of phytosterols compared to cholesterol is due to their expulsion from the enterocytes back in the gut lumen via the ATP-binding cassette transporters. ${ }^{129}$

Dietary intake of phytosterols in humans can lower blood cholesterol by reducing intestinal absorption. In 1953 , Pollack reported a mean reduction of $25 \%$ of total cholesterol in 26 healthy men consuming between 5 and $10 \mathrm{~g} /$ day of sitosterol for between 8 days and 8 months. ${ }^{130}$ Afterward, many studies evaluated the effects of phytosterols on lipid metabolism disorder and atherogenesis in humans and in laboratory animals.

The use of phytosterols in supplements and in food fortification has been limited due to their low solubility. To increase the solubility of nonesterified phytosterols in foods, formulation of emulsions, microemulsions and suspension is currently utilized. ${ }^{131}$ Most of the studies on phytosterols have evidenced their LDL-C-lowering effects, while HDL-C levels do not seem to be influenced by these compounds. ${ }^{132}$ Phytosterols can affect TG plasma levels. In a review of 19 studies, dietary phytosterols reduced TGs by $0.8-28 \%$ compared to the baseline values, with a greater effect in the hypertriglyceridemic subjects. ${ }^{133}$

A recent meta-analysis of 20 studies found no effect of phytosterols on high-sensitivity C-reactive protein levels, an inflammatory biomarker associated with atherosclerosis and coronary heart disease. ${ }^{134}$ Similarly, phytosterols have not demonstrated benefit on endothelial function. $^{135}$

Few intervention studies on phytosterol food fortification or supplementation and cardiovascular mortality are present in literature. The studies that have investigated the association of blood concentrations of phytosterols and risk of cardiovascular diseases reported a direct correlation between phytosterol plasma level and increased cardiovascular risk in some cases ${ }^{136-138}$ and no association in others. ${ }^{139}$ A meta-analysis of these studies did not show a significant association between serum concentration of sitosterol or campesterol and cardiovascular risk. ${ }^{140}$ Data from the European Prospective Investigation into Cancer and Nutrition-the Netherlands study, energy-adjusted dietary intake of naturally occurring phytosterols was not associated with risk of cardiovascular disease, coronary heart disease or myocardial infarction. ${ }^{141}$ However, it must be considered that this population consumed a low amount of phytosterols (mean intake of $296 \mathrm{mg} /$ day) with a narrow range of intake (mean intake of 231 to $366 \mathrm{mg}$ /day from lowest to highest quintile). A metaanalysis of 41 randomized controlled trials involving 3306 subjects reported that sterol and stanol consumption decreased plasma beta-carotene and other carotenoid concentrations but does not affect tocopherol, retinol and vitamin D plasma levels. ${ }^{142}$ Recently, Tao et al ${ }^{143}$ reported that, despite a $50 \%$ reduction in plasma cholesterol, the accumulation of stigmasterol leads to cardiac injury and promote mortality in a rodent model of phytosterolemia (disease characterized by elevated levels of dietary plant sterols in the blood) suggesting a role of phytosterol as potential risk factor for cardiovascular disease when absorbed in large amount.

The main clinical studies on plant substances and MetS are summarized in Table 2. The effects of plant and phytochemicals on the different components of MetS and associated conditions are represented in Table 3.

\section{Conclusion}

Some natural bioactive compounds including polyphenols, silymarin and monacolins could have a beneficial effect on the main features of MetS such as obesity, dyslipidemia, IR, impaired glucose tolerance, liver steatosis and hypertension through different mechanisms.

Green tea catechins, caffeine, berries anthocyanins and cocoa polyphenols evidenced benefits in some characteristics of MetS. RYR monacolins are effective in the treatment of hypercholesterolemia. Curcumin has been shown to interfere with several pathogenetic mechanisms of MetS, but its effectiveness is reduced by poor bioavailability. Combination with piperine or phytosome formulations can improve curcumin absorption and then its effectiveness in metabolic alterations (Figure 1).

In some cases, randomized controlled trials do not confirm the promising effects reported in the previous animal or in vitro studies. Several factors can explain these discrepancies, including poor bioavailability of substances, use of low dosages, inadequate treatment duration and inappropriate statistical approach. Further 


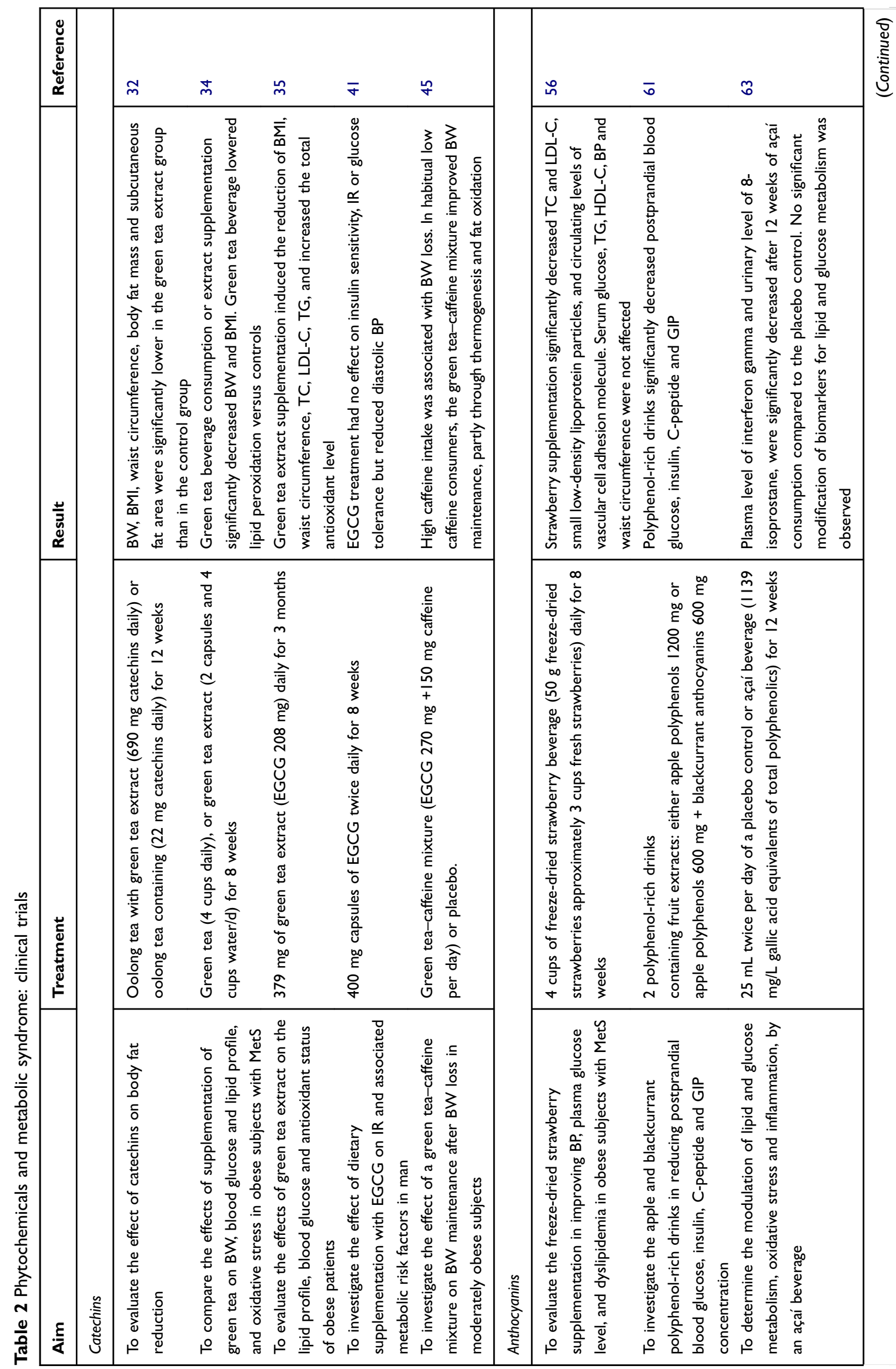




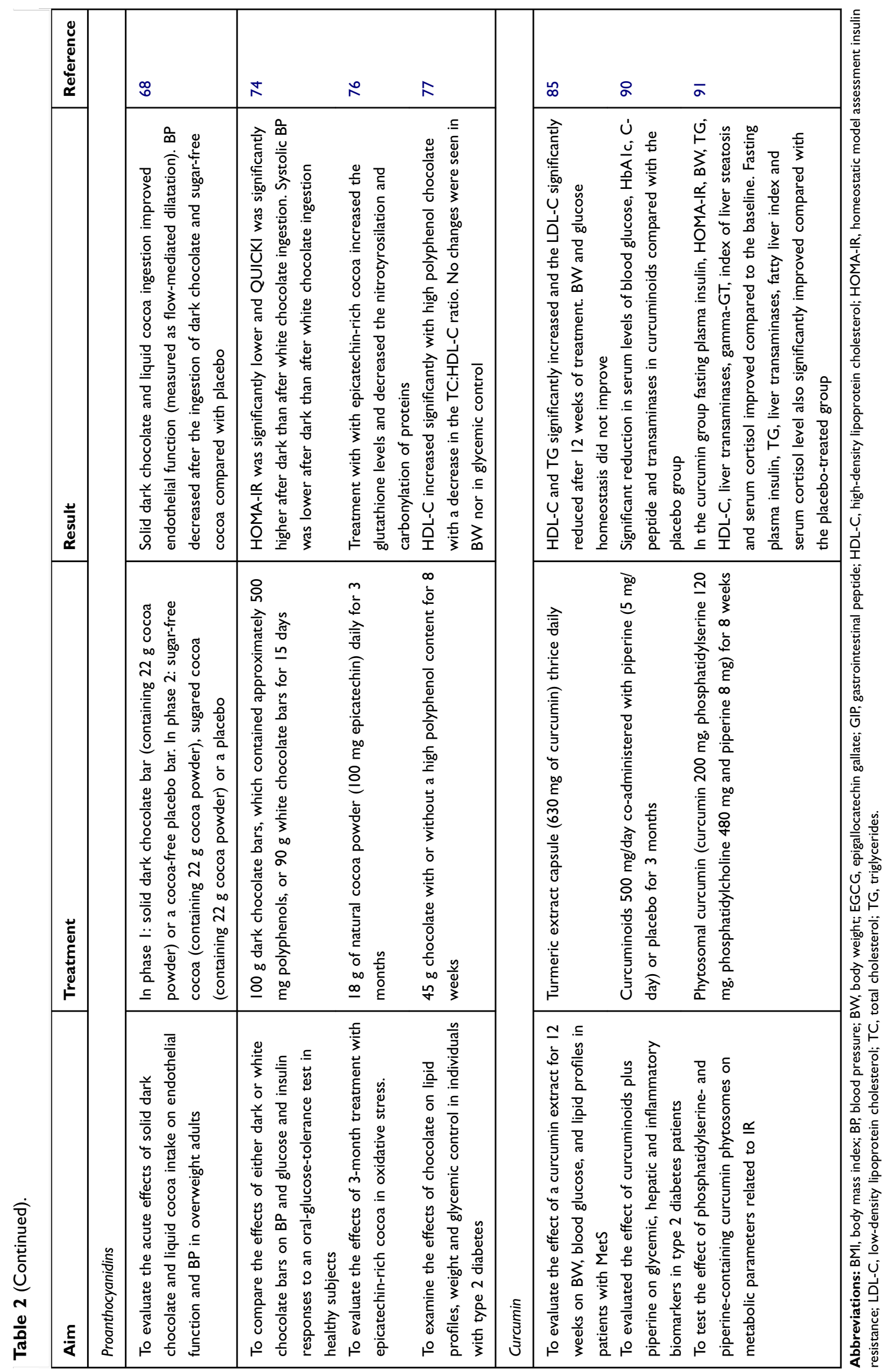


Table 3 Effects of plant substances on the components of metabolic syndrome and associated conditions

\begin{tabular}{|c|c|c|c|}
\hline Components & Plants/substances & Mechanisms & References \\
\hline \multirow[t]{2}{*}{ Abdominal obesity } & Caffeine & Adrenergic stimulation & 36,38 \\
\hline & Tea (catechins) & Adrenergic stimulation & $33-35$ \\
\hline \multirow[t]{2}{*}{$\begin{array}{l}\text { Impaired glucose } \\
\text { tolerance }\end{array}$} & $\begin{array}{l}\text { Berries (anthocyanins, } \\
\text { flavonoids, stilbenes) }\end{array}$ & $\begin{array}{l}\text { Slowing carbohydrate digestion and absorption; stimulating insulin secretion via } \\
\text { AMPK pathway; decreasing cell oxidative damage }\end{array}$ & 62 \\
\hline & $\begin{array}{l}\text { Pomegranate } \\
\text { (ellagitannins, } \\
\text { anthocyanins) } \\
\text { Cocoa } \\
\text { Curcuma (curcumin) } \\
\text { Olive oil (polyphenols) }\end{array}$ & $\begin{array}{l}\text { Inhibition of } \alpha \text {-glucosidase; increasing glucose transporter type } 4 \text { activity } \\
\text { Slowing carbohydrate digestion and absorption; stimulation of incretin } \\
\text { response; improvement of insulin signaling, modulation of gut microbiota. } \\
\text { Improvement of IR via TNF } \alpha \text { reduction } \\
\text { Slowing carbohydrate digestion and absorption; improvement of IR via anti- } \\
\text { inflammatory activity }\end{array}$ & $\begin{array}{l}64 \\
73,74,78,79 \\
87,96 \\
95\end{array}$ \\
\hline Hypertriglyceridemia & $\begin{array}{l}\text { Olive oil } \\
\text { (MUFAs, polyphenols) }\end{array}$ & Increasing VLDL catabolism & 95,96 \\
\hline Low levels of HDL-C & $\begin{array}{l}\text { Curcuma (curcumin)? } \\
\text { Olive oil } \\
\text { (polyphenols) }\end{array}$ & -Improvement of HDL metabolism & $\begin{array}{l}85,86,91 \\
95-97\end{array}$ \\
\hline High blood pressure & $\begin{array}{l}\text { Cocoa (catechins, } \\
\text { proanthocyanidins, } \\
\text { flavonols) } \\
\text { Pomegranate } \\
\text { (ellagitannins, } \\
\text { anthocyanins) } \\
\text { Olive oil } \\
\text { (polyphenols) }\end{array}$ & $\begin{array}{l}\text { Activation of endothelial NO synthase; inhibition of angiotensin-converting } \\
\text { enzyme } \\
\text { Reduction of serum angiotensin-converting enzyme (ACE) activity } \\
\text { Increasing NO levels } \\
\text { Increasing NO levels }\end{array}$ & $\begin{array}{l}67-72 \\
95\end{array}$ \\
\hline \multicolumn{4}{|l|}{ Associated conditions } \\
\hline Fatty liver & $\begin{array}{l}\text { Curcuma (curcumin) } \\
\text { Milk thistle }\end{array}$ & Antioxidant and antiinflammatory effects; inhibition of fibrogenesis & $\begin{array}{l}90,91 \\
104\end{array}$ \\
\hline $\begin{array}{l}\text { Chronic } \\
\text { inflammation }\end{array}$ & $\begin{array}{l}\text { Tea, catechins } \\
\text { Berries (anthocyanins, } \\
\text { flavonols,stilbenes) } \\
\text { Pomegranate } \\
\text { (ellagitannins, } \\
\text { anthocyanins) } \\
\text { Cocoa (catechins, } \\
\text { proanthocyanidins, } \\
\text { flavonols) } \\
\text { Curcuma (curcumin) } \\
\text { Olive oil (polyphenols) }\end{array}$ & $\begin{array}{l}\text { Modulation signaling of inflammatory response pathways, antioxidant activity } \\
\text { NF-kB suppression } \\
\text { Modulating peroxisome proliferator-activated receptor pathways } \\
\text { Modulation of toll-like receptor } \\
\text { pathway } \\
\text { Reduction of TNFa; inhibition of COX and LOS } \\
\text { Inhibition of COX; reduction of inflammatory gene expression }\end{array}$ & $\begin{array}{l}51,52 \\
63 \\
64 \\
69 \\
97\end{array}$ \\
\hline LDL-C/small LDL & $\begin{array}{l}\text { Tea, catechins } \\
\text { Berries (anthocyanins, } \\
\text { flavonoids, stilbenes) } \\
\text { Phytosterols }\end{array}$ & $\begin{array}{l}\text { Reduction of lipid intestinal absorption, upregulation of LDL receptors; } \\
\text { protection of lipid from oxidative damage } \\
\text { Inhibition of cholesterol synthesis via activation of AMPK } \\
\text { Inhibition of intestinal cholesterol absorption }\end{array}$ & $\begin{array}{l}34,35,46-48 \\
60,61,63 \\
130,132- \\
135\end{array}$ \\
\hline
\end{tabular}

Abbreviations: AMPK, $5^{\prime}$ adenosine monophosphate kinase; COX, cyclooxygenase; HDL-C, high-density lipoprotein cholesterol; IR, insulin resistance; LOS, lipooxygenase; MUFAs, monounsaturated fatty acids; NAFLD, nonalcoholic fatty liver disease; NF-kB, nuclear factor kB; NO, nitric oxide; TNF $\alpha$, tumor necrosis factor alpha; VLDL, very low-density lipoprotein. 

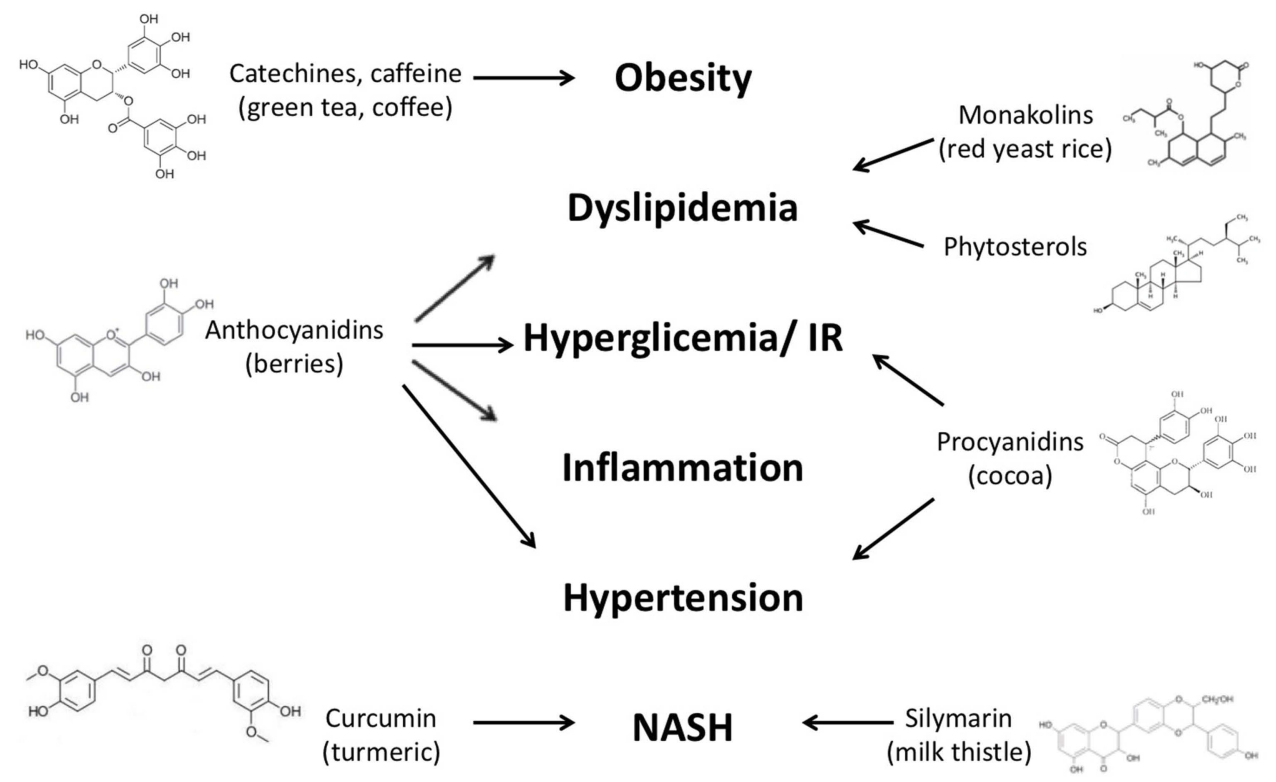

Figure I Effect of natural bioactive compounds on the main features of MetS.

Abbreviations: ALT, alanine aminotransferase; AST, aspartate aminotransferase; BMI, body mass index; cAMP, cyclic adenosine monophosphate; COMT, catechol-O-methyl transferase enzyme; EGCG, epigallocatechin gallate; HDL-C, high-density lipoprotein cholesterol; HOMA-IR, homeostatic model assessment insulin resistance; IR, insulin resistance; LDL-C, low-density lipoprotein cholesterol; MetS, metabolic syndrome; NAFLD, non alcoholic fatty liver disease; NASH, non-alcoholic steatohepatitis; NF-kB, nuclear factor kB; PAI-I, plasminogen activator inhibitor-I; PC, policosanol; TG, triglycerides; TNF $\alpha$, tumor necrosis factor alpha.

long-term randomized and well-designed trials are needed to better understand the role of bioactive compounds in the prevention and treatment of MetS, and alternatives in the supplement formulations are desirable to improve the bioavailability of these substances.

\section{Author contributions}

All authors contributed toward data analysis, drafting and critically revising the paper, gave final approval of the version to be published, and agreed to be accountable for all aspects of the work.

\section{Disclosure}

The authors report no conflicts of interest in this work.

\section{References}

1. Ervin RB. Prevalence of metabolic syndrome among adults 20 years of age and over, by sex, age, race and ethnicity, and body mass index: United States, 2003-2006. Natl Health Stat Report. 2009;5:1-7.

2. Alberti KG, Zimmet PZ. Definition, diagnosis and classification of diabetes mellitus and its complications. Part 1: diagnosis and classification of diabetes mellitus provisional report of a WHO consultation. Diabet Med. 1998;15:539-553. doi:10.1002/(ISSN)1096-9136

3. Expert Panel on Detection, Evaluation, and Treatment of High Blood Cholesterol in Adults. Executive summary of the third report of The National Cholesterol Education Program (NCEP) expert panel on detection, evaluation, and treatment of high blood cholesterol in adults (Adult Treatment Panel III). JAMA. 2001;285:2486-2497. doi:10.1001/jama.285.19.2486.
4. Ford ES. Prevalence of the metabolic syndrome defined by the International Diabetes Federation among adults in the. U.S. Diabet Care. 2005;28:2745-2749. doi:10.2337/diacare.28.11.2745

5. Grundy SM, Brewer HB Jr, Cleeman JI, Smith SC Jr, Lenfant C. American Heart Association; National Heart, Lung, and Blood Institute. Definition of Metabolic Syndrome. Report of the National Heart, Lung and Blood Institute/American Heart Association conference on scientific issues related to definition. Circulation. 2004;109:433-438. doi:10.1161/01.CIR.0000111245. 75752.C6

6. Yang L, Colditz GA. Prevalence of overweight and obesity in the United States, 2007-2012. JAMA Intern Med. 2015;175:14121413. doi:10.1001/jamainternmed.2015.2405

7. Ranasinghe $\mathrm{P}$, Mathangasinghe Y, Jayawardena R, Hills AP, Misra A. Prevalence and trends of metabolic syndrome among adults in the asia-pacific region: a systematic review. BMC Public Health. 2017;17:101. doi:10.1186/s12889-017-4041-1

8. Farrell GC, Haczeyni F, Chitturi S. Pathogenesis of NASH: how metabolic complications of overnutrition favour lipotoxicity and pro-inflammatory fatty liver disease. Adv Exp Med Biol. 2018;1061:19-44. doi:10.1007/978-981-10-8684-7_3

9. Soleimani M. Insulin resistance and hypertension: new insights. Kidney Int. 2015;87:497-499. doi:10.1038/ki.2014.392

10. Henao-Mejia J, Elinav E, Elinav E, Jin C, et al. Inflammasomemediated dysbiosis regulates progression of NAFLD and obesity. Nature. 2012;482:179-185. doi:10.1038/nature10809

11. Skurk T, Alberti-Huber C, Herder C, Hauner H. Relationship between adipocyte size and adipokine expression and secretion. $J$ Clin Endocrinol Metab. 2007;92:1023-1033. doi:10.1210/jc.20061055

12. Hirosumi G, Tuncman L, Chan L, et al. A central role for JNK in obesity and insulin resistance. Nature. 2002;420:333-336. doi:10. 1038/nature01137

13. Marchesini G, Bugianesi E, Forlani G, et al. Nonalcoholic fatty liver, steatohepatitis, and the metabolic syndrome. Hepatology. 2003;37:917-923. doi:10.1053/jhep.2003.50161 
14. Propst A, Propst T, Judmaier G, Vogel W. Prognosis in nonalcoholic steatohepatitis. Gastroenterology. 1995;108:1607. doi:10.101 6/0016-5085(95)90724-6

15. Lau LHS, Wong SH. Microbiota, obesity and NAFLD. Adv Exp Med Biol. 2018;106:111-125.

16. Mehta NN, McGillicuddy FC, Anderson PD, et al. Experimental endotoxemia induces adipose inflammation and insulin resistance in humans. Diabetes. 2010;59:172-181. doi:10.2337/db09-0367

17. Kim JJ, Sears DD. TLR4 and insulin resistance. Gastroenterol Res Pract. 2010;2010:212563. doi:10.1155/2010/212563

18. Babio N, Bulló M, Salas-Salvadó J. Mediterranean diet and metabolic syndrome: the evidence. Public Health Nutr. 2009;12:16071617. doi:10.1017/S1368980009990449

19. Macready AL, George TW, Chong MF, et al. Flavonoid-rich fruit and vegetables improve microvascular reactivity and inflammatory status in men at risk of cardiovascular disease-FLAVURS: a randomized controlled trial. Am J Clin Nutr. 2014;99:479-489. doi:10.3945/ajen.113.074237

20. Martínez-González MA, Salas-Salvadó J, Estruch R, Corella D, Fitó M, Ros E. Benefits of the Mediterranean diet: insights from the PREDIMED study. Prog Cardiovasc Dis. 2015;58:50-60. doi:10.1016/j.pcad.2015.04.003

21. Karalis DG. Achieving optimal lipid goals in the metabolic syndrome: a global health problem. Atherosclerosis. 2014;237:191193. doi:10.1016/j.atherosclerosis.2014.07.039

22. Scalbert A, Manach C, Morand C, Remesy C. Dietary polyphenols and the prevention of diseases. Crit Rev Food Sci Nutr. 2005;45:287-306. doi:10.1080/1040869059096

23. Shahidi F, Naczk M. Food Phenolics, Sources, Chemistry, Effects, Applications. Lancaster: PA Technomic Publishing Co Inc; 1995.

24. Clifford MN, Scalbert A. Ellagitannins-occurrence in food, bioavailability and cancer prevention. J Food Sci Agricol. 2000; 80:118-125.

25. Abourashed EA. Review of stilbenes: applications in chemistry, life sciences and materials science. J Nat Prod. 2017;80:577. doi:10.1021/acs.jnatprod.7b00089

26. Thompson LU, Robb P, Serraino M, Cheung F. Mammalian lignan production from various foods. Nutr Cancer. 1991;16:43-52. doi:10.1080/01635589109514139

27. Beukes N, Levendal RA, Frost CL. Selected terpenoids from medicinal plants modulate endoplasmic reticulum stress in metabolic disorders. $J$ Pharm Pharmacol. 2014;66:1505-1525. doi:10.1111/jphp.12267

28. Patel MD, Thompson PD. Phytosterols and vascular disease. Atherosclerosis. 2006;186:12-19. doi:10.1016/j.atherosclerosis.20 05.10 .026

29. Wang TH, Lin TF. Monascus rice products. Adv Food Nutr Res. 2007;53:123-159. doi:10.1016/S1043-4526(07)53004-4

30. Marinangeli CP, Kassis AN, Jain D, Ebine N, Cunnane SC, Jones PJ. Comparison of composition and absorption of sugarcane policosanols. Br J Nutr. 2007;97:381-388. doi:10.1017/S0007114507336763

31. Del Rio D, Rodriguez-Mateos A, Spencer JP, Tognolini M, Borges GA. Crozier dietary (poly)phenolics in human health: structures, bioavailability, and evidence of protective effects against chronic diseases. Antioxid Redox Signal. 2013;18:1818-1892. doi:10.1089/ ars.2012.4581

32. Nagao T, Komine $\mathrm{Y}$, Soga S, et al. Ingestion of a tea rich in catechins leads to a reduction in body fat and malondialdehyde modified LDL in men. Am $J$ Clin Nutr. 2005;81:122-129. doi:10.1093/ajen/81.1.122

33. Harpaz E, Tamir S, Weinstein A, Weinstein Y. The effect of caffeine on energy balance. J Basic Clin Physiol Pharmacol. 2017;28:1-10. doi:10.1515/jbcpp-2016-0090

34. Basu A, Sanchez K, Leyva MJ, et al. Green tea supplementation affects body weight, lipids, and lipid peroxidation in obese subjects with metabolic syndrome. J Am Coll Nutr. 2010;29:31-40. doi:10.1080/07315724.2010.10719814
35. Suliburska J, Bogdanski P, Szulinska M, Stepien M, PupekMusialik D, Jablecka A. Effects of green tea supplementation on elements, total antioxidants, lipids, and glucose values in the serum of obese patients. Biol Trace Elem Res. 2012;149:315-322. doi:10.1007/s12011-012-9448-z

36. Diepvens K, Westerterp KR, Westerterp-Plantenga MS. Obesity and thermogenesis related to the consumption of caffeine, ephedrine, capsaicin, and green tea. Am J Physiol Regul Integr Comp Physiol. 2007;292:77-85. doi:10.1152/ajpregu.00630.2006

37. Evans BA, Sato M, Sarwar M, Hutchinson DS, Summers RJ. Ligand-directed signalling at beta-adrenoceptors. Br J Pharmacol. 2010;159:1022-1038. doi:10.1111/j.1476-5381.2009.00602.x

38. Collins L, Cornelius M, Voegel LR, Walker JF, Stamford BA. Effect of caffeine and/or cigarette smoking on resting energy expenditure. Int J Obes Relat Metab Disord. 1994;18:551-556.

39. Shixian Q, VanCrey B, Shi J, Kakuda Y, Jiang Y. Green tea extract thermogenesis-induced weight loss by epigallocatechin gallate inhibition of catechol-O-methyltransferase. J Med Food. 2006;9:451458. doi:10.1089/jmf.2006.9.451

40. Gregersen NT, Bitz C, Krog-Mikkelsen I, et al. Effect of moderate intakes of different tea catechins and caffeine on acute measures of energy metabolism under sedentary conditions. $\mathrm{Br} J$ Nutr. 2009;102:1187-1194. doi:10.1017/S0007114509371779

41. Brown AL, Lane J, Coverly J, et al. Effects of dietary supplementation with the green tea polyphenol epigallocatechin-3-gallate on insulin resistance and associated metabolic risk factors: randomized controlled trial. Br J Nutr. 2009;101:886-894. doi:10.1017/S0007114508116270

42. Berube-Parent S, Pelletier C, Dore J, Tremblay A. Effects of encapsulated green tea and Guarana extracts containing a mixture of epigallocatechin-3-gallate and caffeine on $24 \mathrm{~h}$ energy expenditure and fat oxidation in men. Br J Nutr. 2005;94:432-436. doi:10.1079/bjn20051458

43. Boschmann M, Thielecke F. The effects of epigallocatechin-3gallate on thermogenesis and fat oxidation in obese men: A pilot study. J Am Coll Nutr. 2007;26:389-395.

44. Rudelle S, Ferruzzi MG, Cristiani I, Moulin J, Macé K, Acheson K. Effect of a thermogenic beverage on $24 \mathrm{hr}$ energy metabolism in humans. Obesity (Silver Spring). 2007;15:349-355. doi:10.1038/ oby. 2007.535

45. Westerterp-Plantenga MS, Lejeune MP, Kovacs EM. Body weight loss and weight maintenance in relation to habitual caffeine intake and green tea supplementation. Obes Res. 2005;13:1195-1204. doi:10.1038/oby.2005.142

46. Chu SL, Fu H, Yang JX, et al. A randomized double-blind placebocontrolled study of Pu'er tea extract on the regulation of metabolic syndrome. Chin J Integr Med. 2011;17:492-498. doi:10.1007/ s11655-011-0781-4

47. Belcaro G, Ledda A, Hu S, Cesarone MR, Feragalli B, Dugall M. Greenselect Phytosome for borderline metabolic syndrome. Evid Based Complement Alternat Med. 2013;11:1-7.

48. Maki KC, Reeves MS, Farmer M, et al. Green tea catechin consumption enhances exercise-induced abdominal fat loss in overweight and obese adults. J Nutr. 2009;139:264-270. doi:10.3945/ jn. 108.098293

49. Vieira Senger AE, Schwanke CHA, Gomes I, Valle Gottlieb MG. Effect of green tea (Camellia sinensis) consumption on the components of metabolic syndrome in elderly. J Nutr Health Aging. 2012;16:738-742. doi:10.1007/s12603-012-0081-5

50. Yang TY, Chou JI, Ueng KC, Chou MY, Yang JJ, Lin-Shiau SY. Weight reduction effect of Puerh tea in male patients with metabolic syndrome. Phytother Res. 2014;28:1096-1101. doi:10.1002/ ptr.5111

51. Calò LA, Vertolli U, Davis PA, et al. Molecular biology based assessment of green tea effects on oxidative stress and cardiac remodelling in dialysis patients. Clin Nutr. 2014;33:437-442. doi:10.1016/j.clnu.2013.06.010 
52. Mandel SA, Weinreb O, Amit T, Youdim MB. Molecular mechanisms of the neuroprotective/neurorescue action of multi-target green teapolyphenols. Front Biosci (Schol Ed). 2012;1:581-598. doi: $10.2741 / \mathrm{s} 286$

53. Wang H, Nair MG, Strasburg GM, et al. Antioxidant and antiinflammatory activities of anthocyanins and their aglycon, cyanidin, from tart cherries. J Nat Prod. 1999;62:294-296. doi:10.1021/ np980501m

54. Huang WY, Liu YM, Wang J, Wang XN, Li CY. Anti-inflammatory effect of the blueberry anthocyanins malvidin-3-glucoside and malvidin-3-galactoside in endothelial cells. Molecules. 2014;19:12827-12841. doi:10.3390/molecules 190811211

55. Lau FC, Bielinski DF, Joseph JA. Inhibitory effects of blueberry extract on the production of inflammatory mediators in lipopolysaccharideactivated BV2 microglia. J Neurosci Res. 2007;85:10101017. doi:10.1002/(ISSN)1097-4547

56. Kalea AZ, Clark K, Schuschke DA, Klimis-Zacas DJ. Vascular reactivity is affected by dietary consumption of wild blueberries in the Sprague- Dawley rat. $J$ Med Food. 2009;12:21-28. doi:10.1089/jmf.2008.0078

57. Martineau LC, Couture A, Spoor D, et al. Anti-diabetic properties of the Canadian lowbush blueberry Vaccinium angustifolium Ait. Phytomedicine. 2006;13:612-623. doi:10.1016/j.phymed.2006.08.005

58. Vendrame S, Daugherty A, Kristo AS, Riso P, Klimis-Zacas D. Wild blueberry (Vaccinium angustifolium) consumption improves inflammatory status in the obese Zucker rat model of the metabolic syndrome. $J$ Nutr Biochem. 2013;24:1508-1512. doi:10.1016/j.jnutbio.2012.12.010

59. Seymour EM, Singer AA, Kirakosyan A, Urcuyo-Llanes DE, Kaufman PB, Bolling SF. Altered hyperlipidemia, hepatic steatosis, and hepatic peroxisome proliferator-activated receptors in rats with intake of tart cherry. J Med Food. 2008;11:252-259. doi:10.1089/jmf.2007.658

60. Yang L, Ling W, Du Z, et al. Effects of anthocyanins on cardiometabolic health: a systematic review and meta-analysis of randomized controlled trials. Adv Nutr. 2017;8:684-693. doi:10.3945/ an.116.014852

61. Basu A, Fu DX, Wilkinson M, et al. Strawberries decrease atherosclerotic markers in subjects with metabolic syndrome. Nutr Res. 2010;30:462-469. doi:10.1016/j.nutres.2010.06.016

62. Castro-Acosta ML, Stone SG, Mok JE, et al. Apple and blackcurrant polyphenol-rich drinks decrease postprandial glucose, insulin and incretin response to a highcarbohydrate meal in healthy men and women. $J$ Nutr Biochem. 2017;49:53-62. doi:10.1016/j. jnutbio.2017.07.013

63. Kim H, Simbo S, Fang C, et al. Açaí (Euterpe oleracea Mart.) beverage consumption improves biomarkers for inflammation but not glucose-or lipid-metabolism in individuals with metabolic syndrome in a randomized, double blinded, placebo-controlled clinical trial. Food Funct. 2018;9:3097-3103. doi:10.1039/C8FO00595H

64. Medjakovic S, Jungbauer A. Pomegranate: a fruit that ameliorates metabolic syndrome. Food Funct. 2013;4(1):19-39. doi:10.1039/ c2fo30034f

65. Moazzen H, Alizadeh M. Effects of pomegranate juice on cardiovascular risk factors in patients with metabolic syndrome: a doubleblinded, randomized crossover controlled trial. Plant Foods Hum Nutr. 2017;72(2):126-133. doi:10.1007/s11130-017-0605-6

66. Aprotosoaie AC, Miron A, Trifan A, Luca VS, Costache II. The cardiovascular effects of cocoa polyphenols-an overview. Diseases. 2016;17:4.

67. Fisher ND, Hughes M, Gerhard-Herman M, Hollenbergh NK. Flavanol-rich cocoa induces nitric-oxide-dependent vasodilation in healthy humans. $J$ Hypertens. 2003;21:2281-2286. doi:10.10 97/00004872-200312000-00016

68. Faridi Z, Njike VY, Dutta S, Ali A, Katz DL. Acute dark chocolate and cocoa ingestion and endothelial function: a randomized controlled crossover trial. Am J Clin Nutr. 2008;88:58-63. doi:10.10 93/ajcn/88.1.58
69. Magrone T, Russo MA, Jirillo E. Cocoa and dark chocolate polyphenols: from biology to clinical applications. Front Immunol. 2017;8:677. doi:10.3389/fimmu.2017.00677

70. Shiina Y, Funabashi N, Lee K, Murayama T, Nakamura K, Wakatsuki Y. Acute effect of oral flavonoid-rich dark chocolate intake on coronary circulation, as compared with non-flavonoid white chocolate, by transthoracic Doppler echocardiography in healthy adults. Int $J$ Cardiol. 2009;131:424-429. doi:10.1016/j. ijcard.2008.11.048

71. Napoli C, Ignarro LJ. Nitric oxide and pathogenic mechanisms involved in the development of vascular diseases. Arch Pharm Res. 2009;32:1103-1108. doi:10.1007/s12272-009-1801-1

72. Actis-Goretta L, Ottaviani JI, Fraga CG. Inhibition of angiotensin converting enzyme activity by flavanol-rich foods. J Agric Food Chem. 2006;54:229-234. doi:10.1021/jf052263o

73. Grassi D, Lippi C, Necozione S, Desideri G, Ferri C. Short-term administration of dark chocolate is followed by a significant increase in insulin sensitivity and a decrease in blood pressure in healthy persons. Am J Clin Nutr. 2005;81:611-614. doi:10.1093/ ajen/81.3.611

74. Desideri G, Kwik-Uribe C, Grassi D, et al. Benefits in cognitive function, blood pressure, and insulin resistance through cocoa flavanol consumption in elderly subjects with mild cognitive impairment: the cocoa, cognition, and aging (CoCoA) study. Hypertension. 2012;60:794-801. doi:10.1161/ HYPERTENSIONAHA.112.193060

75. Haghighat N, Rostami A, Eghtesadi S, Shidfar F, Heidari I, Hoseini A. The effects of dark chocolate on glycemic control and blood pressure in hypertensive diabetic patients: a randomized clinical trial. Razi J Med Sci. 2013;20:78-86.

76. Ramirez-Sanchez I, Taub PR, Taub PR, Ciaraldi TP, et al. Epicatechin rich cocoa mediated modulation of oxidative stress regulators in skeletal muscle of heart failure and type 2 diabetes patients. Int $J$ Cardiol. 2013;168:3982-3990. doi:10.1016/j.ijcard.2013.06.089

77. Mellor DD, Sathyapalan T, Kilpatrick ES, Beckett S, Atkin SL. High-cocoa polyphenol-rich chocolate improves HDL cholesterol in type 2 diabetes patients. Diabet Med. 2010;27:1318-1321.

78. Dorenkott MR, Griffin LE, Goodrich KM, et al. Oligomeric cocoa procyanidins possess enhanced bioactivity compared to monomeric and polymeric cocoa procyanidins for preventing the development of obesity, insulin resistance, and impaired glucose tolerance during high-fat feeding. J Agric Food Chem. 2014;62:2216-2227. doi: $10.1021 / \mathrm{jf} 500333 \mathrm{y}$

79. Strat KM, Rowley TJ 4th, Smithson AT, et al. Mechanisms by which cocoa flavanols improve metabolic syndrome and related disorders. J Nutr Biochem. 2016;35:1-21. doi:10.1016/j.jnutbio.20 15.12.008

80. Epstein J, Sanderson IR, Macdonald TT. Curcumin as a therapeutic agent: the evidence from in vitro, animal and human studies. $\mathrm{Br} J$ Nutr. 2010;103:1545-1557. doi:10.1017/S0007114509993291

81. Liu W, Zhai Y, Heng X, Che FY, Chen W, Sun D. Oral bioavailability of curcumin: problems and advancements. J Drug Target. 2016;24:694-702. doi:10.3109/1061186X.2016.1157883

82. Gupta SC, Patchva S, Aggarwal BB. Therapeutic roles of curcumin: lessons learned from clinical trials. Aaps J. 2013;15:195-218. doi:10.1208/s12248-012-9432-8

83. Kunnumakkara AB, Bordoloi D, Padmavathi G, et al. Curcumin, the golden nutraceutical: multitargeting for multiple chronic diseases. $\mathrm{Br}$ J Pharmacol. 2017;174:1325-1348. doi:10.1111/bph.13621

84. Milani A, Basirnejad M, Shahbazi S, Bolhassani A. Carotenoids: biochemistry, pharmacology and treatment. $\mathrm{Br} J$ Pharmacol. 2017;174:1290-1324. doi:10.1111/bph.13625

85. Yang YS, Su YF, Yang W, Lee YH, Chou JI, Ueng KC. Lipidlowering effects of curcumin in patients with metabolic syndrome: a randomized, double-blind, placebo-controlled trial. Phytother Res. 2014;28:1770-1777. doi:10.1002/ptr.5197 
86. Alwi I, Santoso T, Suyono S, et al. The effect of curcumin on lipid level in patients with acute coronary syndrome. Acta Med Indones. 2008;40:201-210.

87. Melo ISV, Santos AFD, Bueno NB. Curcumin or combined curcuminoids are effective in lowering the fasting blood glucose concentrations of individuals with dysglycemia: systematic review and meta-analysis of randomized controlled trials. Pharmacol Res. 2018;128:137-144. doi:10.1016/j.phrs.2017.09.010

88. Anand P, Kunnumakkara AB, Newman RA, Aggarwal BB Bioavailability of curcumin: problems and promises. Mol Pharm. 2007;4:807-818. doi:10.1021/mp700113r

89. Shakeri A, Sahebkar A. Opinion paper: phytosome: a fatty solution for efficient formulation of phytopharmaceuticals. Recent Pat Drug Deliv Formul. 2016;10:7-10. doi:10.2174/1872211309666150813152305

90. Panahi Y, Khalili N, Sahebi E, Namazi S, Simental-Mendía LE, Majeed M. A Effects of curcuminoids plus piperine on glycemic, hepatic and inflammatory biomarkers in patients with type 2 diabetes mellitus: a randomized double-blind placebo-controlled trial. Drug Res. 2018;68:403-409. doi:10.1055/s-0044-101752

91. Cicero AFG, Sahebkar A, Fogacci F, Bove M, Giovannini M, Borghi C. Effects of phytosomal curcumin on anthropometric parameters, insulin resistance, cortisolemia and non-alcoholic fatty liver disease indices: a double-blind, placebo-controlled clinical trial. Eur J Nutr. 2019. doi:10.1007/s00394-019-01916-7

92. Tuck KL, Hayball PJ. Major phenolic compounds in olive oil: metabolism and health effects. J Nutr Biochem. 2002;13:636-644. doi:10.1016/S0955-2863(02)00229-2

93. Ruiz-Canela M, Martinez-Gonzalez MA. Olive oil in the primary prevention of cardiovascular disease. Maturitas. 2011;68:245-250. doi:10.1016/j.maturitas.2010.12.002

94. Visioli F, Bernardini E. Extra virgin olive oil's polyphenols: biological activities. Curr Pharm Des. 2011;17:786-804. doi:10.2174/ 138161211795428885

95. Estruch R, Martinez-Gonzalez MA, Corella D, et al. Effects of a Mediterranean-style diet on cardiovascular risk factors: a randomized trial. Ann Intern Med. 2006;145:1-11. doi:10.7326/00034819-145-1-200607040-00004

96. Covas MI, Nyyssonen K, Poulsen HE, et al. The effect of polyphenols in olive oil on heart disease risk factors: a randomized trial Ann Intern Med. 2006;145:333-341. doi:10.7326/0003-4819-1455-200609050-00006

97. Tsartsou E, Proutsos N, Castanas E, Kampa M. Network metaanalysis of metabolic effects of olive-oil in humans shows the importance of olive oil consumption with moderate polyphenol levels as part of the mediterranean diet. Front Nutr. 2019;12:6:6.

98. Ho GT, Kase ET, Wangensteen H, Barsett H. Effect of phenolic compounds from elderflowers on glucose- and fatty acid uptake in human myotubes and HepG2-cells. Molecules. 2017;6:22-90.

99. Sayin FK, Buyukbas S, Basarali K, Alp H, Toy H, Ugurcu V. Effects of Silybum marianum extract on high fat diet induced metabolic disorders in rats. Polish J Food Nutr Sci. 2016;66:4349. doi:10.1515/pjfns-2015-0014

100. Bahmani M, Shirzad H, Rafieian S, Rafieian-Kopaei M. Silybum marianum: beyond hepatoprotection. J Evid Based Complementary Altern Med. 2015;20:292-301. doi:10.1177/2156587215571116

101. Fehér J, Lengyel G. Silymarin in the prevention and treatment of liver diseases and primary liver cancer. Curr Pharm Biotechnol. 2012;13:210-217. doi:10.2174/138920112798868818

102. Tajmohammadi A, Razavi BM, Hosseinzadeh H. Silybum marianum (milk thistle) and its main constituent, silymarin, as a potential therapeutic plant in metabolic syndrome: A review. Phytother Res. 2018;32:1933-1949. doi:10.1002/ptr.6153

103. de Avelar CR, Pereira EM, de Farias Costa PR, de Jesus RP, de Oliveira LPM. Effect of silymarin on biochemical indicators in patients with liver disease: systematic review with meta-analysis. World J Gastroenterol. 2017;23:5004-5017. doi:10.3748/wjg.v23.i27.5004
104. Zhong S, Fan Y, Yan Q, et al. The therapeutic effect of silymarin in the treatment of nonalcoholic fatty disease: A meta-analysis (PRISMA) of randomized control trials. Medicine. 2017;96: e9061. doi:10.1097/MD.0000000000009061

105. Fallahzadeh MK, Dormanesh B, Sagheb MM, et al. Effect of addition of silymarinto rennin angiotensin system inhibitors on proteinuria in type 2 diabetic patients with overt nephropathy: A randomized, double blind, placebocontrolled trial. Am J Kidney Dis. 2012;60:896-903. doi:10.1053/j.ajkd.2012.06.005

106. Zarvandi M, Rakhshandeh H, Abazari M, Shafiee-Nick R, Ghorbani A. Safety and efficacy of a polyherbal formulation for the management of dyslipidemia and hyperglycemia in patients with advanced stage of type 2 diabetes. Biomed Pharmacother. 2017;89:69-75. doi:10.1016/j.biopha.2017.02.016

107. Menendez R, Mas R, Amor MA, et al. Effects of policosanol treatment on the susceptibility of low density lipoprotein (LDL) isolated from healthy volunteers to oxidative modification in vitro. $\mathrm{Br} \mathrm{J}$ Clin Pharmacol. 2000;50:255-326. doi:10.1046/j.1365-2125.2000.00250.x

108. $\mathrm{Ng} \mathrm{CH}$, Leung KY, Huang Y, Chen ZY. Policosanol has no antioxidant activity in human low-density lipoprotein but increases excretion of bile acids in hamsters. J Agric Food Chem. 2005;53:6289-6293. doi:10.1021/jf051269a

109. Kassis AN, Kubow S, Jones PJ. Sugar cane policosanols do not reduce LDL oxidation in hypercholesterolemic individuals. Lipids. 2009;44:391-396. doi:10.1007/s11745-009-3295-5

110. Pons P, Rodriguez M, Robaina C, et al. Effects of successive dose increases of policosanol on the lipid profile of patients with type II hypercholesterolaemia and tolerability to treatment. Int $J$ Clin Pharmacol Res. 1994;14:27-33.

111. Castano G, Fernandez L, Mas R, et al. Comparison of the efficacy, safety and tolerability of original policosanol versus other mixtures of higher aliphatic primary alcohols in patients with type II hypercholesterolemia. Int J Clin Pharmacol Res. 2002;22:55-66.

112. Torres O, Agramonte AJ, Illnait J, Mas Ferreiro R, Fernandez L, Fernandez JC. Treatment of hypercholesterolemia in NIDDM with policosanol. Diabetes Care. 1995;18:393-397. doi:10.2337/ diacare.18.3.393

113. Castano G, Mas R, Arruzazabala ML, et al. Effects of policosanol and pravastatin on lipid profile, platelet aggregation and endothelemia in older hypercholesterolemic patients. Int J Clin Pharmacol Res. 1999;19:105-116.

114. Fernandez JC, Mas R, Castano G, et al. Comparison of the efficacy, safety and tolerability of policosanol versus fluvastatin in elderly hypercholesterolaemic women. Clin Drug Invest. 2001;21:103113. doi:10.2165/00044011-200121020-00003

115. Castano G, Mas R, Fernandez L, et al. Comparison of the efficacy and tolerability of policosanol with atorvastatin in elderly patients with type II hypercholesterolaemia. Drugs Aging. 2003;20:153163. doi:10.2165/00002512-200320020-00006

116. Greyling A, De Witt C, Oosthuizen W, Jerling JC. Effects of a policosanol supplement on serum lipid concentrations in hypercholesterolaemic and heterozygous familial hypercholesterolaemic subjects. Br J Nutr. 2006;95:968-975. doi:10.1079/bjn20061715

117. Berthold HK, Unverdorben S, Degenhardt R, Bulitta M, GouniBerthold I. Effect of policosanol on lipid levels among patients with hypercholesterolemia or combined hyperlipidemia: a randomized controlled trial. JAMA. 2006;295:2262-2269. doi:10.1001/ jama.295.19.2262

118. Francini-Pesenti F, Beltramolli D, Dall'Acqua S, Brocadello F. Effect of sugar cane policosanol on lipid profile in primary hypercholesterolemia. Phytother Res. 2008;22:318-322. doi:10.1002/ptr.2315

119. Francini-Pesenti F, Brocadello F, Beltramolli D, Nardi M, Caregaro L. Sugar cane policosanol failed to lower plasma cholesterol in primitive, diet-resistant hypercholesterolaemia: a double blind, controlled study. Complement Ther Med. 2008;16:61-65. doi:10.1016/ j.ctim.2007.08.003 
120. Lin Y, Rudrum M, van der Wielen RP, et al. Wheat germ policosanol failed to lower plasma cholesterol in subjects with normal to mildly elevated cholesterol concentrations. Metabolism. 2004; 53:1309-1314. doi:10.1016/j.metabol.2004.05.006

121. Dulin MF, Hatcher LF, Sasser HC, Barringer TA. Policosanol is ineffective in the treatment of hypercholesterolemia: a randomized controlled trial. Am J Clin Nutr. 2006;84:1543-1548. doi:10.1093/ ajen/84.6.1543

122. European Food Safety Authority. Scientific opinion on the substantiation of health claims related to policosanols from sugar cane wax and maintenance of normal blood LDL-cholesterol concentrations (ID 1747, 1748, 1864, 1951, 1954, 4693) and maintenance of normal blood HDL-cholesterol concentrations (ID 1747, 1748, 1864, 1951, 1954, 4693) pursuant to Article 13 (1)of Regulation (EC) No 1924/2006. Efsa J. 2011;9(6):2255.

123. Racette SB, Lin X, Ma L, Ostlund RE Jr. Natural dietary phytosterols. J AOAC Int. 2015;98:679-684. doi:10.5740/jaoacint. SGERacette

124. Cho KH, Yadav D, Kim SJ, Kim JR. Blood pressure lowering effect of cuban policosanol is accompanied by improvement of hepatic inflammation, lipoprotein profile, and HDL quality in spontaneously hypertensive rats. Molecules. 2018;3:23.

125. Park HJ, Yadav D, Jeong DJ, et al. Short-term consumption of Cuban policosanol lowers aortic and peripheral blood pressure and ameliorates serum lipid parameters in healthy Korean participants: randomized, double-blinded, and placebo-controlled study. Int $J$ Environ Res Public Health. 2019;5:16.

126. Vanhanen HT, Miettinen TA. Effects of unsaturated and saturated dietary plant sterols on their serum contents. Clin Chim Acta. 1992;205:97-107. doi:10.1016/s0009-8981(05)80004-x

127. Ostlund RE, McGill JB, Zeng CM, et al. Gastrointestinal absorption and plasma kinetics of soy delta(5)-phytosterols and phytostanols in humans. Am J Physiol Endocrinol Metab. 2002;282:E911E916. doi:10.1152/ajpendo.00328.2001

128. Ostlund RE. Phytosterols, cholesterol absorption and healthy diets. Lipids. 2007;42:41-45. doi:10.1007/s11745-006-3001-9

129. Ikeda I, Tanaka K, Sugano M, Vahouny GV, Gallo LL. Inhibition of cholesterol absorption in rats by plant sterols. J Lipid Res. 1988;29:1573-1582.

130. Pollak OJ. Reduction of blood cholesterol in man. Circulation. 1953;7:702-706. doi:10.1161/01.cir.7.5.702

131. Rozner S, Garti N. The activity and absorption relationship of cholesterol and phytosterols. Colloids Surf A. 2006;282-283:435456. doi:10.1016/j.colsurfa.2005.12.032

132. Shaghaghi MA, Abumweis SS, Jones PJH. Cholesterol-lowering efficacy of plant sterols/stanols provided in capsule and tablet formats: results of a systematic review and meta-analysis. $J$ Acad Nutr Diet. 2013;113:1494-1503. doi:10.1016/j.jand.2013.07.006
133. Rideout TC, Marinangeli CP, Harding SV. Triglyceride-lowering response to plant sterol and stanol consumption. J AOAC Int. 2015;98:707-715. doi:10.5740/jaoacint.SGERideout

134. Rocha VZ, Ras RT, Gagliardi AC, Mangili LC, Trautwein EA, Santos RD. Effects of phytosterols on markers of inflammation: a systematic review and meta-analysis. Atherosclerosis. 2016; 248:76-83. doi:10.1016/j.atherosclerosis.2016.01.035

135. Ras RT, Fuchs D, Koppenol WP, et al. The effect of a low-fat spread with added plant sterols on vascular function markers: results of the investigating vascular function effects of plant sterols (INVEST) study. Am J Clin Nutr. 2015;101:733-741. doi:10.3945/ ajcn.114.102053

136. Sudhop T, Gottwald BM, von Bergmann K. Serum plant sterols as a potential risk factor for coronary heart disease. Metabolism. 2002;51:1519-1521. doi:10.1053/meta.2002.36298

137. Assmann G, Cullen P, Erbey J, Ramey DR, Kannenberg F, Schulte H. Plasma sitosterol elevations are associated with an increased incidence of coronary events in men: results of a nested casecontrol analysis of the Prospective Cardiovascular Munster (PROCAM) study. Nutr Metab Cardiovasc Dis. 2006;16:13-21. doi:10.1016/j.numecd.2005.04.001

138. Silbernagel G, Fauler G, Hoffmann MM, et al. The associations of cholesterol metabolism and plasma plant sterols with all-cause and cardiovascular mortality. J Lipid Res. 2010;51:2384-2393. doi:10.1194/jlr.P002899

139. Windler E, Zyriax BC, Kuipers F, Linseisen J, Boeing $H$. Association of plasma phytosterol concentrations with incident coronary heart disease Data from the CORA study, a case-control study of coronary artery disease in women. Atherosclerosis. 2009;203:284-290. doi:10.1016/j.atherosclerosis.2008.06.014

140. Genser B, Silbernagel G, De Backer G, et al. Plant sterols and cardiovascular disease: a systematic review and meta-analysis. Eur Heart J. 2012;33:444-451. doi:10.1093/eurheartj/ehr441

141. Ras RT, van der Schouw YT, Trautwein EA, Sioen I, Dalmeijer G, Zock PL. Intake of phytosterols from natural sources and risk of cardiovascular disease in the European Prospective Investigation into Cancer and Nutrition-the Netherlands (EPIC-NL) population. Eur J Prev Cardiol. 2015;22:1067-1075. doi:10.1177/204748731 4554864

142. Baumgartner S, Ras RT, Trautwein EA, Mensink RP, Plat J. Plasma fat-soluble vitamin and carotenoid concentrations after plant sterol and plant stanol consumption: a meta-analysis of randomized controlled trials. Eur J Nutr. 2017;56:909-923. doi:10.1007/s00394016-1289-7

143. Tao C, Shkumatov AA, Alexander ST, Ason BL, Zhou M. Stigmasterol accumulation causes cardiac injury and promotes mortality. Commun Biol. 2019;2:20. doi:10.1038/s42003-0180245-x

Diabetes, Metabolic Syndrome and Obesity: Targets and Therapy

Dovepress

\section{Publish your work in this journal}

Diabetes, Metabolic Syndrome and Obesity: Targets and Therapy is an international, peer-reviewed open-access journal committed to the rapid publication of the latest laboratory and clinical findings in the fields of diabetes, metabolic syndrome and obesity research. Original research, review, case reports, hypothesis formation, expert opinion and commentaries are all considered for publication. The manuscript management system is completely online and includes a very quick and fair peer-review system, which is all easy to use. Visit http://www.dovepress.com/testimonials.php to read real quotes from published authors.

Submit your manuscript here: https://www.dovepress.com/diabetes-metabolic-syndrome-and-obesity-targets-and-therapy-journal 